\title{
Urgences
}

\section{Le mouton de carotte}

\section{René-Jacques Gallant et Pauline Pinard}

Numéro 8, 4e trimestre 1983

Littérature jeunesse

URI : https://id.erudit.org/iderudit/025118ar

DOI : https://doi.org/10.7202/025118ar

Aller au sommaire du numéro

Éditeur(s)

Urgences

ISSN

0226-9554 (imprimé)

1927-3924 (numérique)

Découvrir la revue

Citer ce document

Gallant, R.-J. \& Pinard, P. (1983). Le mouton de carotte. Urgences, (8), 43-47. https://doi.org/10.7202/025118ar

Ce document est protégé par la loi sur le droit d'auteur. L’utilisation des services d'Érudit (y compris la reproduction) est assujettie à sa politique d'utilisation que vous pouvez consulter en ligne.

https://apropos.erudit.org/fr/usagers/politique-dutilisation/
Cet article est diffusé et préservé par Érudit.

Érudit est un consortium interuniversitaire sans but lucratif composé de l'Université de Montréal, l'Université Laval et l'Université du Québec à Montréal. Il a pour mission la promotion et la valorisation de la recherche. https://www.erudit.org/fr/ 


\section{RENÉ-JACQUES GALLANT}

(collaboration de Pauline Pinard)

\section{Le mouton de carotte}

Théâtre de marionnettes 


\section{LE MOUTON DE CAROTTE}

Carotte (couché ou non): Atchoum... ah! que je suis... atchoum... malade; j'ai attrapé un gros rhume; vous les amis avez-vous déjà eu le rhume? (Carotte se mouche), j'ai mal à la tête, ... atchoum... (Carotte se frotte souvent le nez comme pour s'empêcher d'éternuer). Je crois que j'ai un peu de fièvre, je suis mieux de me coucher,... atchoum... Ah! j'entends mon grand-père qui arrive, on va lui jouer un bon tour ( $r i$ res), je vais faire semblant de dormir.

Grand-père: Bonjour les enfants! Ah! le Carotte, il a été jouer dehors sans son gilet de laine. Et voilà qu'il a attrapé un vilain rhume. Ah! oui, j'oubliais Bruno et Isabelle sont venus lui apporter une jolie fleur pour le réconforter. Tiens, je vais la poser ici, près de lui. Papa et maman m'ont confié la maison aujourd'hui et ils $\mathrm{m}^{\prime}$ ont demandé de veiller à ce que Carotte se repose bien toute la journée de façon à ce qu'il guérisse rapidement. (Le grand-père se penche sur Carotte qui se retourne). Je crois que Carotte s'est endormi.

Carotte (En criant): Grand-père!

(Le Grand-père se sent mal, gesticule, etc...)

Grand-père: Ah! ah! mon petit sacripan, tu m'as fait peur! Cette fois tu es mieux de dormir, et ne fais pas semblant.

Carotte: Oh! Grand-père, je veux bien dormir, mais ici dans cette chambre, je m'ennuie tout seul. (temps) Grand-père, je voudrais avoir un mouton. 
Grand-père: Un mouton,... mais un mouton Carotte on ne trouve pas ça dans les villes. Les moutons sont sur les fermes à la campagne.

Carotte: Je veux un mouton, bon! sinon je ne dors pas.

Grand-père: Carotte, je voudrais bien t'en donner un mouton, si je pouvais, mais où veux-tu que je trouve un mouton et comment feras-tu pour le garder ici?

Carotte: Moi, je veux un mouton!

Grand-Père: Bon, il est tard maintenant Carotte et tu dois dormir. Bonne nuit!

Carotte: Grand-père, chante-moi une chanson!

Grand-père: Bon, O.K., mais fermes tes yeux. (Chant: Au jardin de Pierrot). Bon, maintenant je crois qu'il s'est endormi. (Le grand-père sort).

(La fleur se réveille. Marguerite s'étire, prend vie...)

Marguerite: Bonjour les amis, je suis Marguerite, je suis une fleur magique. Est-ce que votre ami Carotte a de la peine? (Réponse des enfants) Qu'est-ce qui ferait bien plaisir à Carotte? (Réponse) Un mouton? Eh bien soit! prononcez la formule magique avec moi et nous allons faire apparaître un mouton, O.K.? Répétez après moi: Alibaba, pyjama un mouton apparaîtra, Carotte réveille-toi!

(Le mouton apparaît et Carotte se réveille). 
Carotte: Ah! mon joli mouton...

(Bêlements du mouton)

(Carotte embrasse le mouton)

Carotte: Eh! les amis, est-ce que vous savez qui m'a donné ce mouton? (Réponse des enfants). Ah! comme elle est gentille, cette Marguerite!

Marguerite (Elle apparaît): Bonjour Carotte!

Carotte: Bonjour Marguerite! Quoi? Tu es capable de parler, même si tu es une fleur...

Carotte: Quoi? Tu es capable de parler, même si tu es une fleur...

Marguerite: Oui, car je suis une fleur magique et maintenant je dois partir visiter d'autres amis malades qui ont besoin de moi. Au revoir et soigne-toi bien.

(Carotte demeure seul avec le mouton).

Carotte: Tu sais mouton, je t'aime bien, mais je ne peux te garder ici, je n'ai rien à te donner pour te nourrir et mon grand-père ne voudra pas que je te garde ici.

(Bêlements du mouton) Écoute j'ai une idée, je vais t'habiller chaudement et ainsi tu pourras partir à la campagne, pour trouver une ferme où l'on voudra bien te loger. (Carotte habille le mouton, le mouton s'en va. Carotte se couche). 
Maintenant je peux dormir. (temps).

(Coccorico, chant du coq: coq en scène).

Carotte (II s'étire, se réveille): Ah! C'est déjà le matin, en tout cas je me sens mieux, je crois que je suis guéri.

(Arrivée de Grand-père)

Grand-père: Bonjour, Carotte, comment te sens-tu, as-tu passé une bonne nuit?

Carotte: Oh! Grand-père, il m'est arrivé une aventure merveilleuse. Tu sais cette nuit, j'ai eu la visite d'un mouton.

Grand-père: Mais c'est impossible, Carotte.

Carotte: C'est la vérité, Grand-père... et je sais maintenant que chaque fois que j'aurai un gros rhume, mon mouton viendra me voir. Prends-moi dans tes bras Grand-père et saluons les amis car il est temps de se dire au revoir.

$$
\text { Bye, bye... }
$$

